\title{
For-profit clinics are legal but "no solution"
}

Dr. Christian Hobden is accustomed to fixing what's broken. As chief of emergency medicine at Cité de la Santé in Laval, he oversaw the task of turning around Quebec's most overcrowded emergency department. He was then invited to serve on an expert committee to supervise the rebuilding of emergency departments across Quebec. But he's not likely to be welcome on that committee for much longer. On Oct. 12, Hobden and 2 other emergency department doctors, Dr. Luc Bessette and Dr. Alain Chamoun, effectively abandoned medicare. They opened MDPlus, a full private medical clinic located near the affluent neighbourhoods of Outremont and Mount Royal in Montréal.

MD-Plus is one of just a handful of user-pay general practice clinics in the country. The Canadian Union of Public Employees' new report, Innovation Exposed (http://www.cupe.ca /updir/Innovation_exposed.pdf) - an inventory of private initiatives in Canada's health care system - found private, forprofit MRI clinics in Nova Scotia and Newfoundland and Labrador; in Quebec, more than 50 private clinics - including at least 14 for-profit MRI facilities - offer diagnostic tests, cataract surgeries and orthopedic procedures to paying patients.

MD-Plus charges $\$ 100$ for a 20-minute appointment. The doctors take only 2 appointments an hour and promise no waiting for appointments, next-day results on lab tests and thorough follow-up care.

The motivation, Hobden insists, is not greed, but a desire to escape dehumanizing working conditions and to practise good medicine. "With the low rates paid by the Régie de l'assurance maladie du Québec the only way to make a decent living is through volume or by working 80 hours a week," Hobden says. "I don't know of any professional seeing 8,9 or 10 patients an hour who can do the job right."

Quebec Health Minister Philippe Couillard dismisses the clinic as "legal - but no solution for the health care system."

"This kind of initiative will not help anyone in society." Nor, he contends, is it likely to be popular. As of late October, only 79 of the province's 16000 doctors had opted out. "Doctors lose a big advantage by opting out of the public insurance scheme. I'm sure they will find that out soon."

There is nothing new - or illegal - about opting out of medicare. In the early 1970s, hundreds of doctors in Quebec, and many elsewhere in Canada, refused to participate in medicare. But demand for their services dwindled, with few people willing to pay for services offered free through medicare, so most of the hold-outs eventually opted in.

Senator Michael Kirby, who chaired the Senate committee on the federal role of health care, says much of the debate surrounding the opening of MDPlus concentrated on the clinic's legality, while ignoring the pressures that led to its creation.

"As waiting lines have gotten longer or as it's gotten more difficult to find a family physician, increasingly people with money are saying, "To hell with it, I'm going to buy the service," Kirby says. "As long as service continues to deteriorate, more and more people who can afford it are going to opt out and pay the money. It's reversing the trend of the 1970s."

"The real issue is, how are governments prepared to deal with the waiting lines issue? Because if they don't, by stealth, you will end up with a parallel, private system."

CUPE and other groups, such as the Canadian Health Coalition, were so frustrated by what they saw as the federal government's failure to enforce the Canada Health Act that they mounted a legal challenge in 2002. Last September, Federal Court Justice Richard Mosley dismissed the lawsuit. But Mosley did not dismiss the groups' arguments on privatization - instead, he referred the matter back to Parliament.

The author of the CUPE report, Stan Marshall, says they will continue to press Parliament to prevent the proliferation of private, parallel health care. "The more those thrive, the greater is the potential that the public system will be weakened," Marshall says.

Kirby and his committee agree. "We're absolutely opposed to a parallel, private system," he says. "What we're saying is, either you invest enough to make the system work, or you recognize, frankly, that's what's going to happen. By deliberately rationing supply in order to save money, governments have created this problem. Now they have to solve it."

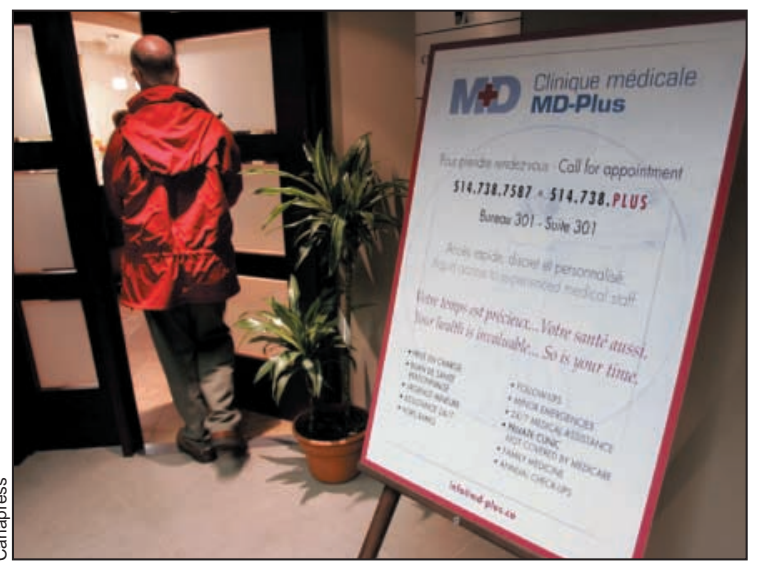

An open door to for-profit health services at MD-Plus in Montréal.

Will MD-Plus thrive, or even survive? Hobden says they will outlast critics like Couillard. But business is not yet brisk at the private clinic, and it's a costly facility to run. Barred from practising in Quebec now that they've opted out of the provincial scheme, late last month, Hobden's partner Dr. Luc Bessette was moonlighting next door in New Brunswick, doing a weeklong stint in a short-handed hospital. - Loreen Pindera, Montréal 